Halsschild etwas breiter als lang, fast parallelseitig, vorn wenig braiter als an der Basis. Punktierung ziemlich kräftig und sebr dicht. - Flügeldecken länglich oval, doppelt so lang wie breit; die grölste Breite liegt in der Mitte. Punktstreifen sehr kräftig; dio Punkte greifen die schmalen, fast rippenförmigen Zwischenräume an. - Schenkel fein und spitz gezähnt, Klauen frei.

Färbung schwarz. - Behaarung kaum sichtbar, fast staubförmig. Die Seiten der Decken stellenweise, ebenso Kopf und Halsschild sparsam mit kleinen grlinen Schüppchen besetzt. - L. : 4-5 mm.

Himalaya-Gebiet: Kurseong und Darjeeling.

\title{
Kurze Bemerkungen über Rüsselkäfer.
}

Von Eduard Vots, Spandau-Waldsiedlung.

1. In den Proc. Linn. Soc. N. S. Wales 1899 , p. 619 , beschreibt Lea einen Eups puncticollis aus Australien. Der gleiche Name wurde bereits 1859 von Boheman vergeben. Ich schlage den Namen Eu, leai für das Tier vor.

2. Euops puncticollis Schilsky - Käfer Eur. 42,92 - möge aus dem gleichen Grunde Eu. schilskyi benannt sein.

3. Im Jahre 1888 beschrieb Peringuey in den Trans. d. Afric. Phil. Soc. VI, p. 135, einen Apoderus miniatus. Da dieser Name bereits 1882 von Faust an eine ostindische Art ver'geben worden war, luderte Peringuey 1892 diesen Namen in cardinalis um. Frust hatte 1893 in Unkenntnis dieser Namensänderung dafür den Namen peringueyi vorgeschlagen, der nunmehr mit miniatus Pering. synonym zu cardinalis Pering. ist.

4. Gleichzeitig wiederum mit cardinalis beschrieb Peringuey einen Apoderus balteatus, ein Name, der 1874 von Roelofs an eine japanische Art vergeben worden war. Für diesen Namen. schlage ich Apod. balteus vor.

5. Auch Apoderus uniformis Sharp - Trans. ent. Soc. London 1889 , p. 51 - mufs umbenannt werden, da der Name von Gyllenhal an eine Art aus Madagascar vergeben worden ist. Diese Art möge Apod. sharpi benannt sein.

6. Scepticus noxius Fst. Als bemerkenswerter Beleg für die vertikale Verbreitung dieser Art möge folgender Fundort dienen : Turkestan, Beik-Akai in $5000 \mathrm{~m}$ Höhe am 1.-3. Okt. 1889 von Conradt gesiebt (Zool. Mus. Berlin, coll. auct.). 